\section{Fundamental dietary patterns and their correlates among US whites}

\author{
MARILYN TSENG, PhD; ROBERT F. DEVELLIS, PhD
}

Bureau-determined poverty threshold (3), with poverty-income $\leq 1$ considered at or below poverty level. Occupations were considered working class if they fell into any 1 of 8 categories (4): clerical administrative support; sales; private household service; other service except protective; precision production, craft, and repair; machine operators, assemblers, and inspectors; transportation or material moving; and handlers, equipment cleaners, and laborers. Residences were categorized into 1 of 4 geographic regions: Northeast, Midwest, South, and West (3). Urban residence was defined as location in the central or fringe counties of metropolitan areas with a population $\geq 1$ million ( 3 ).

Physical activity level was assessed by summing frequencies during the past month of walking a mile or more at a time without stopping, of 7 leisure-time activities (running, biking, swimming, aerobics, dancing, gardening or yard work, and calisthenics or exercises), and of up to 4 other self-reported activities with an intensity rating of 3.0 or greater (3). Based on summed frequencies of beer, wine, and liquor intake from the FFQ, subjects were categorized as nondrinkers ( 0 drinks/day) or as light ( $>0$ to $<1 / 2 \mathrm{drink} / \mathrm{day})$, moderate $(1 / 2$ to $<2$ drinks/day), or heavy ( $\geq 2$ drinks/day) drinkers. Body mass index (measured as $\mathrm{kg} / \mathrm{m}^{2}$ ), based on measurements made at a mobile examination center, was categorized as $<25,25$ $<30$, and $\geq 30$ (5). Waist-to-hip ratio was calculated as the ratio of waist to buttock circumference. Waist:hip $>0.95$ for men and $>0.8$ for women was considered elevated (6).

\section{Data Analysis}

Patterns of food intake were identified by principal components analysis on $\mathrm{FFQ}$ responses in 5,788 persons with information on at least 50 food items. Because we were interested in fundamental dietary patterns occurring across gender and across geographic regions of the United States, we conducted analyses in women and men separately, and in each of the 4 regions, resulting in separate analyses for each of 8 sex-region groups. For each group, we constructed a matrix of correlations among standardized monthly intake frequencies for the 62 food items. The correlation matrix was entered into the principal components analysis using PROC FACTOR in SAS (version 6.12, 1994, SAS Institute, Cary, NC). The results presented here are 
Table 1

Range of factor loadings across 8 sex-region groups ${ }^{a}$, and median frequencies of intake per month for foods ${ }^{b}$ associated with dietary patterns $(N=5,788)$

\begin{tabular}{|c|c|c|c|c|}
\hline Food item & $\begin{array}{l}\text { Range of factor } \\
\text { loadings }\end{array}$ & $\begin{array}{l}\text { Lowest } \\
\text { (quartile 1) }\end{array}$ & $\begin{array}{l}\text { Middle } \\
\text { (quartiles 2-3) }\end{array}$ & $\begin{array}{l}\text { Hlghest } \\
\text { (quartile 4) }\end{array}$ \\
\hline \multicolumn{5}{|l|}{ Vegetable-fruit pattern } \\
\hline Tossed salad & $56-65$ & 3.5 & 9 & 17 \\
\hline Broccoli & $53-62$ & 0 & 3 & 9 \\
\hline Carrots & $52-62$ & 1 & 4 & 13 \\
\hline \multicolumn{4}{|l|}{ Other fruits besides citrus, } & 30 \\
\hline \multicolumn{5}{|l|}{ Brussels sprouts and } \\
\hline cauliflower & $42-53$ & 0 & 1 & 4 \\
\hline \multicolumn{5}{|l|}{ Spinach, greens, collards, } \\
\hline \multicolumn{5}{|l|}{ Peppers (green, red, } \\
\hline yellow) & $33-57$ & 0 & 2 & 4 \\
\hline Chicken & $30-51$ & 4 & 8 & 10 \\
\hline Cabbage & $30-47$ & 1 & 2 & 4 \\
\hline & \multicolumn{4}{|c|}{ Dark breads and rolls } \\
\hline Rice & $27-43$ & $\begin{array}{l}0 \\
1\end{array}$ & 3 & $\begin{array}{r}20 \\
4\end{array}$ \\
\hline Soup/stew & $27-41$ & 1 & 3 & 4 \\
\hline Fish & $19-43$ & 2 & 4 & 4 \\
\hline \multicolumn{5}{|l|}{$\begin{array}{l}\text { Peaches, nectarines, } \\
\text { apricots, guava, }\end{array}$} \\
\hline mango, papaya & $18-47$ & 0 & 0 & 3 \\
\hline$\alpha$ coefficient & $0.72-0.76$ & $\ldots$ & $\ldots$ & $\ldots$ \\
\hline$\%$ variation explained $^{d}$ & $7.2-7.8$ & $\cdots$ & $\cdots$ & $\cdots$ \\
\hline \multicolumn{5}{|l|}{ Red meat-starch pattern } \\
\hline Beef & $49-69$ & 4 & 9 & 17 \\
\hline Processed meats & $41-57$ & 1 & 4 & 13 \\
\hline White potatoes & $40-61$ & 5 & 13 & 17 \\
\hline Pork/ham & $39-52$ & 1 & 3 & 4 \\
\hline Salted snacks & $38-52$ & 2 & 4 & 13 \\
\hline White bread & $36-48$ & 6 & 17 & 30 \\
\hline Cheese & $32-51$ & 4 & 9 & 17 \\
\hline Cheese dishes & $25-49$ & 0 & 2 & 4 \\
\hline Egg & $21-41$ & 2 & 4 & 9 \\
\hline$\alpha$ coefficient ${ }^{c}$ & $0.57-0.67$ & & & \\
\hline$\%$ variation explained ${ }^{d}$ & $4.9-6.1$ & & & \\
\hline
\end{tabular}

${ }^{a}$ Analyses were conducted in women and in men separately, and in the Northeast, Midwest, South, and West regions of the United States separately.

Food items are from food frequency questionnaire used in the third National Health and Nutrition Examination Survey (2)

"Calculated as $\left(\frac{N}{N-1}\right)\left(\frac{S^{2}-\Sigma S^{2}}{S^{2}}\right)$, where $N=$ number of food items in questionnaire, $S^{2}=$ variance of scale scores, and $\Sigma S^{2}=$ sum of variances of $i$ individual scale items (9).

${ }^{\mathrm{C}} \mathrm{Ca}$ culated as eigenvalue for component/total eigenvalues of correlation matrix $(9)$.

based on the unweighted correlation matrix, but the correlation matrix weighted according to the sampling design was similar.

Principal components extraction was followed by orthogonal rotation of retained components. Number of components to retain was based on examination of scree plots (7-9), interpretability $(7,9)$, and other research $(1,10-12)$. Each rotated component was interpreted based on foods with loadings on the component $\geq 0.30$. We used Cronbach's $\alpha$ coefficient (13) to evaluate internal consistency for each component.

To create scales to quantify level of intake of each pattern across all 8 sexregion groups, we first identified sets of definite and possible foods to attach to each pattern. Definite foods had factor loadings $\geq 0.30$ in all 8 groups and lower loadings on other components $(<0.25)$. Possible foods had loadings $\geq 0.20$ in at least 6 of the 8 groups and lower loadings for other components. We then calculated Cronbach's $\alpha$ for definite and possible foods together. If removal of a possible food from the set resulted in a higher average coefficient $\alpha$ for the 8 groups, it was excluded from the scale. Component scores were calculated as the unweighted sum of standardized in- take frequencies for foods associated with the pattern.

Dietary pattern correlates were examined among 4,440 subjects with complete covariate information. We performed multivariate logistic regression analyses for polychotomous outcomes using generalized logits to model the odds of falling into either the lowest or highest vs middle quartiles (14), while adjusting for age (single years), sex, and region. Models were run in SUDAAN (version 7.5.3, 1999, Research Triangle Institute, Research Triangle Park, NC) to take into account the sampling design.

\section{RESULTS AND DISCUSSION}

The 2-factor principal components analysis solution produced dietary patterns that occurred across all 8 sex-region groups (Table 1). The first pattern, which we labeled "vegetable-fruit," was high in vegetables, fruits, dark bread, poultry, and fish. The second, which we labeled the "red meat-starch" pattern, included red meats, potatoes, white bread, eggs, and cheese. Median monthly intake frequencies of the foods characterizing each pattern ranged from zero or once a month in the lowest quartile to as high as once every day in the highest quartile of intake. Dietary patterns identified beyond the first 2 components were less interpretable and not reproducible across groups.

Generally, characteristics and behaviors associated with high intake of 1 pattern were associated with low intake of the other (Table 2). Factors associated with high intake of the vegetable-fruit pattern and low intake of the red meatstarch pattern were older age, female gender, urban residence, more education, attempted weight loss, more frequent physical activity, and supplement use. Conversely, being male, living at or below poverty level, working class status, adding salt more frequently at the table, and smoking were associated with low intake of the vegetable-fruit pattern and high intake of the red meat-starch pattern. High intake of the vegetablefruit pattern was also associated with having breakfast every day and wine consumption, while high intake of the red meat-starch pattern was associated with heavy total alcohol drinking.

The 2 dietary patterns we observed resemble those from other principal components analysis-based studies in the US (10-12,15-18), Canada (19,20), and Great Britain $(21,22)$. As in our analysis, other studies found vegetable-rich dietary pat- 
Table 2

Adjusted odds ratios and $95 \%$ confidence intervals for lowest and highest quartiles of each dietary pattern by sociodemographic and lifestyle characteristics $(\mathrm{N}=4,440)$

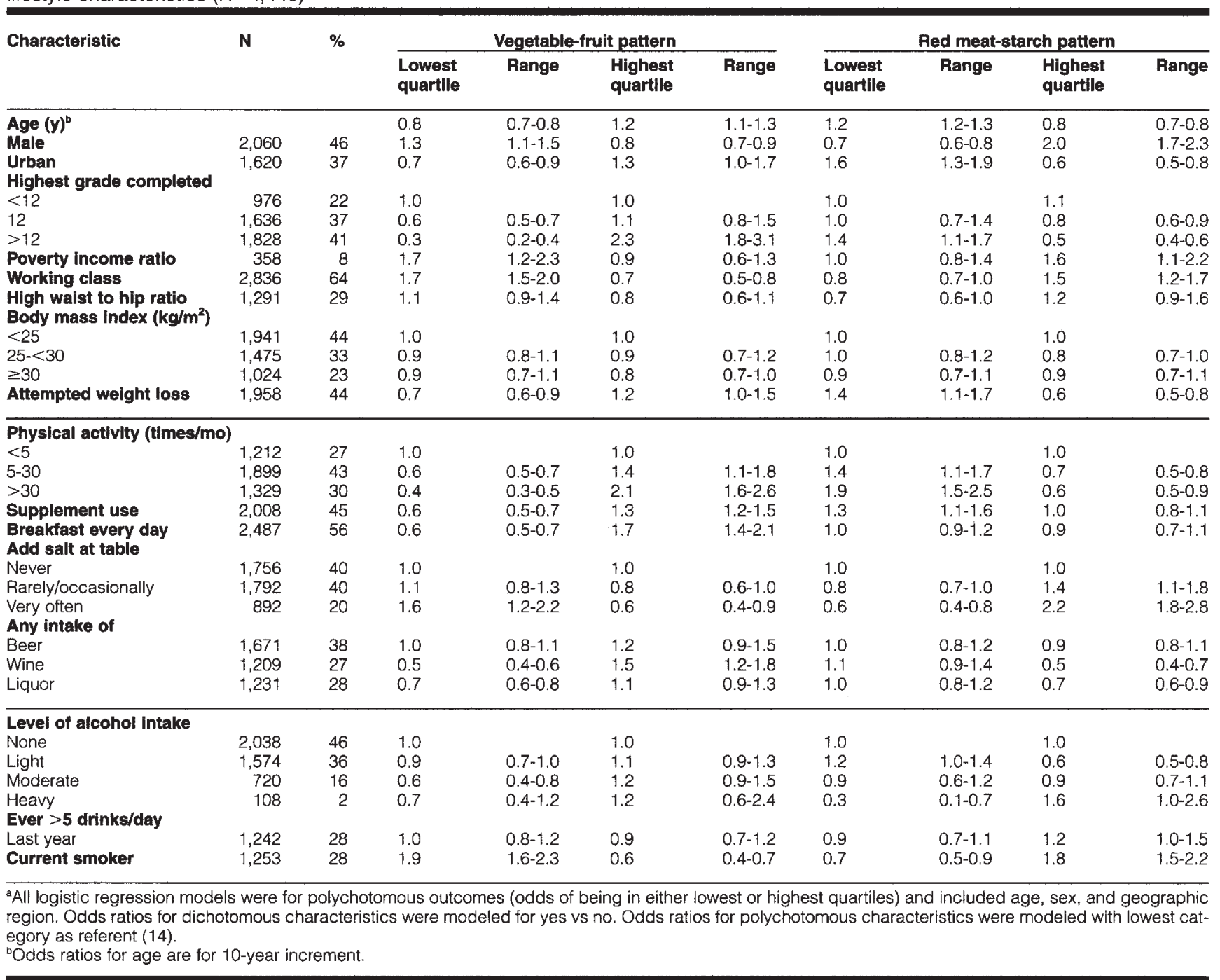


terns to be associated with being female $(19,22)$, having higher socioeconomic position (19-22), and performing healthconscious behaviors (20-23), whereas patterns high in red meat and refined grains were associated with being male $(19,20,22)$, rural residence (21), lower socioeconomic position (22), and smoking $(20,23)$. These findings reflect the transformation of eating habits that occurred early in the 20th century that affected some segments of society more than others (1). Messages targeted at middle-class women by scientists, food corporations, and the government reshaped traditional attitudes toward diet and promoted the idea of eating to stay healthy. In the working and rural poor, however, who had a less secure and less diverse food supply, traditional attitudes prevailed (1).

Most previous studies identified more than 2 dietary patterns, reflecting cultural differences in some instances $(12,17,21)$. More generally, they reflect different criteria for determining the number of components to retain for interpretation. We retained 2 components based on examination of scree plots $(7$. $9)$, interpretability $(7,9)$, prior knowledge $(1,24,25)$, and reproducibility across geographic regions. Other important patterns may exist. However, their identification should be based on knowledge of their characteristics from social, historical, anthropological, or dietary data, and their measurement requires an appropriate dietary instrument to capture the food items of interest. In our study, a dietary questionnaire designed for use in a broad national sample allowed us to identify the broad dietary patterns underlying national dietary habits. Whether measurement of fundamental patterns is a useful way to characterize intake in diet-disease investigations or whether measurement of more specific patterns is necessary requires further study.

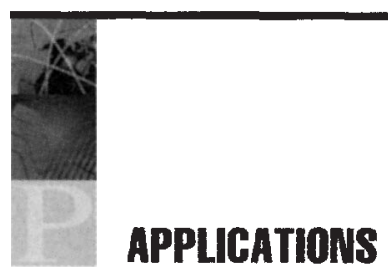

Confirmation of expected associations between dietary patterns and socio- demographic and lifestyle factors supports the validity of principal components analysis-based scales to quantify dietary pattern intake in nutritional epidemiologic studies. Quantitative measurement of dietary patterns has been informative in epidemiologic investigations of various health outcomes (11, $12,17,26,27)$. By focusing on overall diet, a pattern approach captures multiple nutrient effects not readily studied by focusing on single dietary components. Recent studies have demonstrated the usefulness of a pattern approach in dietary interventions $(28,29)$. Dietary pattern measurement in observational studies will contribute to evaluating the potential of a pattern approach for preventing a wide variety of diseases.

\section{References}

1. Levenstein HA. Revolution at the Table: The Transformation of the American Diet. New York: NY: Oxford University Press; 1988.

2. US Dept of Health and Human Services, $\mathrm{Na}$ tional Center for Health Statistics. Plan and Operation of the Third National Health and Nutrition Examination Survey, 1988-94. Hyattsville, Md: Centers for Disease Control and Prevention; 1994 3. US Dept of Health and Human Services, National Center for Health Statistics. Third National Health and Nutrition Examination Survey, 19881994. NHANES III Household Adult Data File. [CD-ROM]. Hyattsville, Md: Centers for Disease Control and Prevention; 1996. Public Use Data File Documentation No. 77560.

4. Krieger $\mathrm{N}$. Overcoming the absence of socioeconomic data in medical records: validation and application of a census-based methodology. Am J Public Health. 1992;92:703-710.

5. WHO Expert Committee. Physical status: the use and interpretation of anthropometry. Report of a WHO Expert Committee. World Health Organ Tech Rep Ser. 1995;854:1-452.

6. US Dept of Agriculture. Report of the Dietary Guidelines Advisory Committee on the Dietary Guidelines for Americans, 1990. Washington, DC: US Dept of Agriculture; 1990.

7. DeVellis RF. Scale Development Theory and Applications. Newbury Park, Calif: Sage Publications: 1991.

8. Kline P. An Easy Guide to Factor Analysis. New York, NY: Routledge; 1994.

9. Hatcher L. A Step-by-Step Approach to Using the SAS System for Factor Analysis and Structural Equation Modeling. Cary, NC: SAS Institute, Inc; 1994

10. Hu F, Rimm E, Smith-Warner $S$, Feskanich D Stampfer M, Ascherio A, Sampson L, Willett $W$ Reproducibility and validity of dietary patterns assessed with a food-frequency questionnaire. Am J Clin Nutr. 1999;69:243-249.

11. Slattery ML, Boucher KM, Caan BJ, Potter JD Ma KN. Eating patterns and risk of colon cancer. Am J Epidemiol. 1998;148:4-16.

12. Tseng $M$, DeVellis RF, Kohlmeier $L$, Khare $M$ Maurer KR, Everhart JE, Sandler RS. Patterns of food intake and gallbladder disease in Mexican Americans. Public Health Nutr. 2000;3:233-243.
13. Cronbach $L J$. Coefficient aipha and the internal structure of tests. Psychometrika. 1951 16:297-334

14. Stokes ME, Davis CS, Koch GG. Categorical Data Analysis Using the SAS System. Cary, NC SAS Institute Inc; 1995.

15. Randall E, Marshall JR, Graham S, Brasure J Patterns in food use and their associations with nutrient intakes. Am J Clin Nutr. 1990:52:739-745. 16. Hebert JR, Kabat GC. Implications for cancer epidemiology of differences in dietary intake associated with alcohol consumption. Nutr Cancer. 1991:15:107-119.

17. Wolff $\mathrm{CB}$, Wolff HK. Maternal eating patterns and birth weight of Mexican American infants. Nutr Health. 1995;10:121-134.

18. Gallagher ML, Farrior E Broadhead L, Gillette LS, Rowe ML, Somes G, West P, Kolasa KM. Development and testing of a food frequency recall instrument for describing dietary patterns in adults and teenagers. Nutr Res. 1993;13:177-188. 19. Beaudry M, Galibois 1, Chaumette P. Dietary patterns of adults in Quebec and their nutritional adequacy. Can J Public Health. 1998;89:347-351. 20. Nolan CC, Gray-Donald K, Shatenstein B, O'Loughlin J. Dietary patterns leading to high fat intake. Can J Public Health. 1995;86:389-391

21. Barker ME, McClean SI, Thompson KA, Reid NG. Dietary behaviours and sociocultural demographics in Northern Ireland. Br I Nutr. 1990;64:319-329

22. Whichelow MJ, Prevost AT. Dietary patterns and their associations with demographic, lifestyle and health variables in a random sample of British adults. Br J Nutr. 1996;76:17-30.

23. Randall $E$, Marshall JR, Graham S, Brasure J. High-risk health behaviors associated with various dietary patterns. Nutr Cancer. 1991:16: 135-151.

24. McIntosh EN. American Food Habits in Historical Perspective. Westport, Conn: Praeger Publishers; 1995.

25. Pillsbury R. No Foreign Food: The American Diet in Time and Place. Boulder, Colo: Westview Press; 1998.

26. Randall E, Marshall JR, Brasure J, Graham S. Dietary patterns and colon cancer in western New York. Nutr Cancer. 1992:18:265-276.

27. Hu FB, Rimm EB, Stampfer MJ, Ashcerio A, Spiegelman D, Willett WC. Prospective study of major dietary patterns and risk of cornoary heart disease in men. Am J Clin Nutr. 2000;72:912-921. 28. Appel $L$, Moore $T$, Obarzanek E Vollmer $W$ Svetkey L, Sacks F. Bray G, Vogt T, Cutler J. Windhauser $M$, Lin $P$, Karanja N. A clinical trial of the effects of dietary patterns on blood pressure. NEngl J Med. 1997;336:1117-1124.

29. de Lorgeril M, Salen $P$, Martin J, Monjaud I Boucher $P$. Mamelle N. Mediterranean dietary pattern in a randomized trial: prolonged survival and possible reduced cancer rate. Arch intern Med. 1998;158:1181-1187.

The authors thank Joanne Dorgan, $M P H, P h D$, and Alison Evans, ScD, for their comments regarding the development of this article. This research was supported by grant No. R25 CA57708 from the National Institutes of Health. 